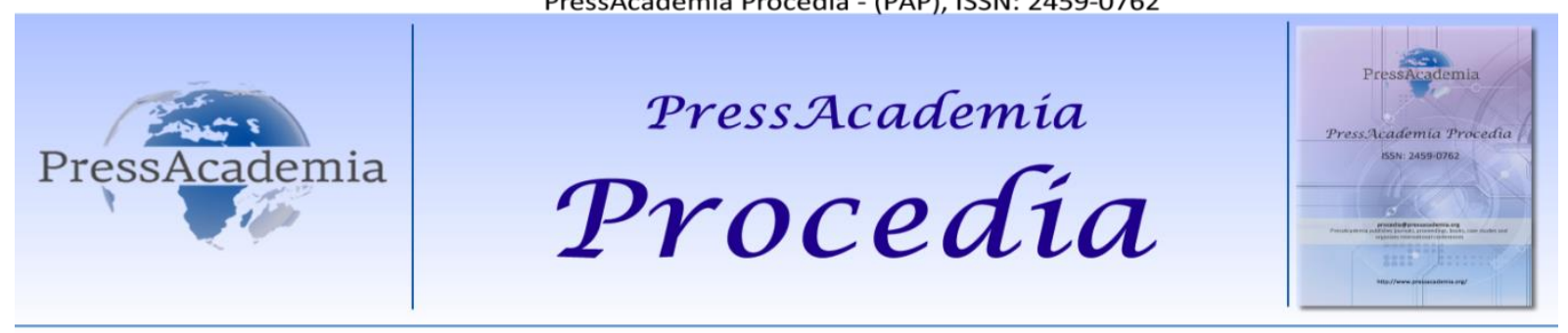

Global Business Research Congress (GBRC), May 24-25, 2017, Istanbul, Turkey

\title{
MARKET STRUCTURE AND EFFECTS OF THE BANKING SECTOR
}

\section{DOI: 10.17261/Pressacademia.2017.400}

PAP-GBRC-V.3-2017(15)-p.143-152

Yasemin Deniz Koc ${ }^{1}$, Sibel Celik ${ }^{2}$, Salih Arslan ${ }^{3}$

${ }^{1}$ Dumlupınar Üniversitesi Uygulamalı Bilimler Yüksekokulu Bankacılık ve Finans Bölümü, Kütahya, Türkiye. denizkoc12@gmail.com

${ }^{2}$ Dumlupınar Üniversitesi Uygulamalı Bilimler Yüksekokulu Sigortacılık ve Risk Bölümü, Kütahya, Türkiye. sibel.celik@dpu.edu.tr

${ }^{3}$ Dumlupınar Üniversitesi Uygulamalı Bilimler Yüksekokulu Bankacılık ve Finans Bölümü, Kütahya, Türkiye. saliharslandpu@hotmail.com

Koc, Y.D., S. Celik and S. Arslan, (2017), Market structure and effects of the bankıng sector. PressAcademia Procedia (PAP), V.3, p.143-152 Permemant link to this document: http://doi.org/10.17261/Pressacademia.2017.400

Copyright: Published by PressAcademia and limited licenced re-use rights only.

\begin{abstract}
In this study, the market structure of the Turkish banking sector was investigated between 2004-2014. Herfindahl- Hirschman Index This result is important in the banking sector in terms of the efficient use of resources and the demonstration of the efficiency of savings into investments: This result supports the findings of Claessens and Laeven (2004), Abbasoğlu et al. (2007), Özcan (2012), Uzgören and Tarhan (2012), in the literatüre. CR4 and Herfindahl-Hirschman the calculation of the Index study the Turkish banking sector have reached the conclusion a monopolistic competitive market structure.
\end{abstract}

Keywords: CR4 concentration analysis, Herfindahl-Hirschman Index, Turkish Banking Sector, market structure.

JEL Codes: G20, G21

\section{BANKACILIK SEKTÖRÜNÜN PIYASA YAPISI VE ETKILERI}

\section{ÖZET}

Bu çalışmada 2004-2014 yılları arasında Türk Bankacılık sektörünün piyasa yapısı araştırılmıştır. Herfindahl- Hirschman Endeksi Bu sonuç bankacılık sektöründe kaynakların verimli kullanılması ve tasarrufların yatırımlara dönüşme etkinliğinin göstergesi olması açısından önemli olup; literatürde Claessens ve Laeven (2004), Abbasoğlu vd. (2007), Özcan (2012), Uzgören ve Tarhan (2012)'nin bulgularını desteklemektedir. CR4 ve Herfindahl-Hirschman Endekslerinin hesaplandığı çalışmada Türk Bankacılık sektörünün monopolcü rekabet piyasa yapısına sahip olduğu sonucuna ulaşılmıştır.

Anahtar Kelimeler: CR4 yoğunlaşma analizi, Herfindahl-Hirschman Endeksleri, Türk Bankacılık Sektörü, piyasa yapısı. JEL Kodları: G20, G21

\section{GiRiş}

Bankacılık sektörü finansal sistemin temelini oluşturan en önemli sektörlerden biridir. Bu nedenle ekonomiyi ve piyasaları etkileyen tüm gelişmeler anında bankacılık sektörünü etkileyerek bankaların temel işlevi olan tasarruf ve yatırım sahiplerine aracılık faaliyetini zorlaştırmaktadır. Bankalar bu işlevi ile kaynakların en uygun alanlara tahsisini sağlayarak kaynakların etkin kullanılamama problemini ortadan kaldırmayı amaçlamaktadır. Kaynakların piyasa yapıcıları arasında etkin dağılmaması farklı piyasa yapısı türlerini ortaya çıkarmıştır. 
Ekonomi biliminde tam rekabet piyasası, monopol piyasası, oligopol piyasası ve monopolcü rekabet piyasası olmak üzere dört çeşit piyasa yapısı vardır (Dinler, 2002; 285). Genel itibariyle n sayıda alıcı ve satıcının olduğu tam rekabet piyasasında kaynaklar etkin bir şekilde kullanılırken; tam rekabet piyasasına en yakın piyasa olan çok sayıda satııı $n$ sayıda alıcının bulunduğu monopolcü rekabet piyasasında bu etkinlik azalmakta; birkaç firmanın sektörün büyük bir bölümüne hakim olduğu oligopol piyasasında ise yoğunlaşma oranı artarken kaynakların etkin kullanımı daha da azalmakta; tek satıcı çok sayıda alıcının bulunduğu monopol piyasasında ise kaynaklar etkin kullanılmamaktadır (Kostakoğlu, 2015; 130).

Piyasa yapısının en önemli belirleyicisi ise piyasa yoğunlaşmasıdır. Genel anlamda yoğunlaşma kavramı, belirli bir endüstride, tek bir firmanın veya az sayıda firmanın fiyat ve üretim düzeyini kontrol altına alması şeklinde ifade etmektedir (Güneş vd.,1997; 34). Endüstrideki firma sayısı ve bu firmaların sektörden aldıkları pay miktarı yoğunlaşma oranının belirleyicisidir (Shy, 1995; 171). Sektörde faaliyet gösteren firma sayısının artması yoğunlaşma oranını azaltırken, bir ya da birkaç firmanın üretimin büyük bir kısmını karşılaması sektördeki yoğunlaşma oranını artırmaktadır (Yıldırım vd., 2012;3839).

Bankacılık sektörünü etkileyen iç ve dış etkenler sektör yoğunlaşmasında değişmelere sebep olduğu gibi, yoğunlaşmada meydana gelen değişiklikler de bankacılık sektörünü etkilemektedir. Bu doğrultuda 2004-2014 dönemi için, piyasa yoğunlaşma oranları ile Türk bankacılık sektörünün piyasa yapısının tespiti çalışmanın amacını oluşturmaktadır. Bu çerçevede çalışma beş bölümden oluşmaktadır. Girişi takiben ikinci bölümde literatür incelemesi, üçüncü bölümde analizde kullanılan veri ve metodoloji yer alırken dördüncü bölümde ampirik bulgular yorumlanmış, sonuç bölümünde çalışmanın genel değerlendirmesi yapılarak önerilerde bulunulmuştur.

\section{LITERATÜR TARAMASI}

Literatürde bankacılık sektörünün piyasa yapısını inceleyen çok sayıda çalışma mevcuttur. Bu çalışmalarda; yoğunlaşma oranının ülkeden ülkeye farklıık gösterebildiği gibi, aynı ülkede farklı dönemlerde de değişebildiği gözlemlenmiştir (Aydınlı 1996; Yayla, 2007; Abbasoğlu vd., 2007; Coşkun vd., 2012; Mirzaei vd., 2013).Panzer Rosse metodunu bankacılık sektöründe ilk kez kullanan Shaffer (1982), Amerika'daki bankaların monopolcü rekabet piyasa yapısına sahip olduğunu tespit ederken; Bikker ve Groeneveld (1998) 1989-1996 dönemi için Avrupa Birliği ülkelerinde; Weill (2004) 12 Avrupa ülkesinde, 1994 ve 1999 yılları için; Casu ve Girardone (2006), 16 Avrupa ülkesinde 1997 ve 2003 dönemi için benzer sonuçlara ulaşmışlardır.Nathan ve Neave (1989) ise Kanada bankacılık sektöründe 1982 yılında tam rekabet, 1983-1984 yılarında ise monopolcü rekabet piyasa yapısının geçerli olduğunu ortaya koyarken; Shaffer (1993) Kanada bankacılık sektöründe 19681989 dönemi için tam rekabet piyasa koşullarının geçerli olduğu bulgularına ulaşmıştır.Bikker ve Haaf (2002a) sanayileşmiş 23 ülkeyi analiz ettikleri çalışmada, monopolcü rekabet piyasasının hakim olduğunu, bazı ülkelerde ise tam rekabet piyasasının geçerli olduğunu tespit ederken; Bikker (2003) Avrupa Birliği ülkelerinin tamamında tam rekabet piyasasının geçersiz olduğunu belirlemiştir. Suominen (1994) 1980'lerin sonunda Finlandiya bankacılık sektörünün bazı bankacılık hizmetlerinde tekel yapıya sahip olduğunu tespit etmiştir. Guillen vd. (2014) ise Latin Amerika ülkeleri bankacılık sektöründe oligopolistik piyasa yapısının geçerli olduğu bulgusuna ulaşmıştır. Gelişmişlik düzeylerine göre ülke gruplarının yoğunlaşma farklılıklarını analiz eden Mirzaei vd. (2013) ise 1999-2008 döneminde gelişmiş ülkelerdeki yoğunlaşma oranlarının gelişmekte olan ülkelere göre daha az olduğu belirlemiştir. Northcott (2004) bankacılık sektöründe yoğunlaşma ve rekabet ilişkisine yönelik araştırmaları özetlediği çalışmasında piyasa gücünün bulunduğu sektörlerde bankaların kredileri daha iyi takip altına alarak kredi kalitesini yükselttikleri, ayrıca riskli yatırımları minimize etmeye çalıştıkları bulgularına ulaşmıştır. Fiona (2006) 1994-2005 dönemi için Amarikanbakacılık sektöründe, yoğunlaşmanın artması durumunda faiz ve faiz dışı gelirlerin arttığı, borç verme faiz oranlarını yükseltici yönde etkide bulunduğu, ancak mevduat faiz oranları üzerinde baskı oluşturduğu sonuçlarına ulaşmıştır.

Türk bankacılık sektörünün piyasa yapısına yönelik olarak yapılan çalışmalarda ise; Claessens ve Laeven (2004), 1994-2001 dönemi için; Abbasoğlu vd. (2007) 2001 ve 2005 yılları için; Özcan (2012) 2002 ve 2009 yılları arasında; Uzgören ve Tarhan (2012)'da 2008 döneminde Türk bankacılık sektörü piyasa yapısının monopolcü rekabet piyasası özelliklerine sahip olduğu sonucuna ulaşırken, Aydınlı (1996), 1991-1992 yıllarında monopol yapıya sahip olan bankacılık sektörünün, 1992-1994 yılları arasında monopolden monopolcü rekabet piyasa yapısına doğru değişime uğradığı sonucuna ulaşmıştır. Kasman (2001) 1988-1996 dönemi için; Gelos ve Roldos (2002)'da 1994-2000 döneminde Türk bankacılık sistemi piyasa yapısının monopolistik bir özellik gösterdiğini ortaya koyarken; Türk bankacılık sektörü piyasa yapısının dönemlere göre farklılık gösterdiğini belirten Çelik ve Kaplan (2010), Türk bankacılık sektörünü 2002 ve 2007 dönemi için incelediği çalışmasında, 2002 ve 2004 yılları arasında monopol yapıda olan sektörün, 2006 yılında rekabetçi hale geldiğini, 2007 yılında ise piyasanın tekrar tekel yapıya dönüştüğünü tespit etmiştir. Yayla (2007) Türk bankacılık piyasasında, 1995-1999 döneminde hem banka sayısının artması hem de sektör koşullarındaki gelişmelerden dolayı yoğunlaşmanın azaldığı, 2000-2005 döneminde ise ekonomik krizinde etkisiyle bazı bankaların birleşmesi bazı bankaların da sistemden çıkması sonucu banka sayısının önemli miktarda azalmasıyla yoğunlaşmanın arttığını tespit etmiştir. 


\section{VERI VE METODOLOJi}

\subsection{Veri}

Çalışmada 2004-2014 yılları arasında 26 ticaret bankası1 için mevduat, kredi ve varlık büyükleri bazında üç ayrı HerfindahlHirschman Yoğunlaşma Endeksi hesaplanarak Türk bankacılık sektörünün piyasa yapısı test edilecektir.

\subsection{Metodoloji}

Piyasa yoğunlaşmasının ölçümünde; Herfindahl-Hirschman, Hannah ve Kay, K-Banka Yoğunlaşma, Rosenbluth-Hall-Tideman, Kapsamlı Yoğunlaşma, Entropi, Hakimiyet ve Hause endeksleri kullanılmaktadır. Endüstriyel iktisat yazınında en çok kullanılan Herfindahl- Hirschman Endeksi, piyasadaki tüm bankaları hesaplamaya dâhil eden bir endekstir2. Bu endeks, Rhoades'e göre (1993) piyasa yoğunlaşmasının istatistiksel olarak ölçülmesidir. Piyasadaki her firmanın piyasa paylarının önce karesi alınıp sonra bu sonuçların toplanması yolu ile hesaplanan HHI endeksi değeri 0 ile 10.000 arasında değerler almaktadır. HHE değerlerinin 1800'ü aşması durumunda piyasa yoğunlaşmasının başladığı, 1000 ile 1800 aralığının ise kabul edilebilir sınırlar olduğu öne sürülmektedir (Yayla, 2007). Hesaplanan değer; 0-1000 arasında ise düşük piyasa yoğunlaşması, 1000-1800 aralığında orta düzey piyasa yoğunlaşması, 1800-10000 aralığında ise yüksek piyasa yoğunlaşması olduğunu göstermektedir (Parkin, 2003; 203). Bankacılık sektöründeki yoğunlaşmayı ölçmek amacı ile kullanılan K-Banka Yoğunlaşma Endeksi (Crk) en yaygın kullanılan endekslerden biri olup, endeks değeri 0 ile 1 arasında değerler almaktadır. Sektörde tekel bankanın 1'e, teorik olarak birbirine yakın büyüklükte sonsuz bankanın ise 0'a yakınlaştığı, banka sayısının (k)'ya göre hesaplandığı bir endekstir3. Hannah ve Kay Endeksi (HKI) banka birleşmeleri ile piyasaya yeni bankaların giriş-çıkış yapması sonucu, sektördeki banka sayılarının değişmesi durumunda sektör yoğunlaşmasının nassl etkilediğini ölçmede kullanılan bir endekstir4. Piyasadaki banka sayısındaki değişme sonucu yoğunlaşmada meydana gelen değişimleri gösteren a esneklik parametresi, aynı zamanda piyasadaki bankalar arasında gerçekleştirilen gelirtransfer esnekliğinin de göstergesidir (Bikker ve Haaf, 2000; 10). HKı değer aralığının alt limiti a sonsuza yakınsarken en büyük bankanın sektördeki payının tersi, üst limiti ise sektördeki banka sayısıdır. Bu durumda piyasadaki mevcut bankaların ortalama büyüklüklerinden daha küçük bir banka sektöre giriş yaptığında HKI değeri azalmakta, ortalamanın üstünde bir banka sektöre girdiğinde ise HKI değeri artmaktadır. Rossenbluth-Hall-Tideman Endeksi (RHTI)'in temel yaklaşımı, her bir bankanın piyasa payını sektördeki sıralamasına göre belirlemektir 5 . Böylece banka sayısı ve bankanın sektör içindeki sıralaması endeks değerini belirlemektedir. 0 ile 1 arasında değer alan endeks, piyasada tekel durumu söz konusu ise 1 değerini, Pazar payı birbirine yakın olan sonsuz sayıda banka olması durumunda ise 0 değerini almaktadır (Yayla, 2007). HH endeks değerinden türetilen Kapsamlı Yoğunlaşma Endeksi (CCI), ilgili sektördeki büyük firmaların etkisinin daha fazla dikkate alınması amacıyla geliştirilmiştir6. Böylece yoğunlaşmayı hesaplamaya yönelik olarak geliştirilen diğer endekslere göre hem göreli yayılma hem de mutlak üstünlük daha etkili olmaktadır. Sektördeki lider firmanın payına, diğer firmaların ağırlık katsayısının çarpımı ile bulunmuş olan paylarının karelerinin eklenmesi suretiyle hesaplanan bu endeks 0 ile 1 arasında değer almaktadır. Endeks değerinin 1'e yakınlaşması durumunda tekel piyasası söz konusu olmaktadır (Yayla, 2007). H endeksi ile aynı özelliklere sahip olan Entropi Endeksi, firmaların piyasa paylarının o payların logaritması ile çarpımı ile elde edilir. Ex-ante beklentileri hesaplamaya dahil eden, teorik alt yapısını bilgi teorisinden alan ve bilgi teorisinde olasılık dağılımı $(p$,$) tarafından temsil$ edilen belirsizliğin bir ölçütüdür7 (Bikker ve Haaf, 2000; 12). Entropy değeri 0 ile logaritma $n$ arasında gerçekleşir. Sıfıra

1 Ziraat banaksı,Halkbankası, Vakıfbank, Akbank, Anadolubank, Şekerbank, Tekstil Bank, Turkishbank, TEB, Garantibankası, İşbankası, Yapıkredi Bankası, Alternatifbank, Arap Türk Bankası, Citibank, Denizbank, Deutsche Bank, Finansbank, HSBC, ING, Habibbank, JPmorgan, SocieteGenerate
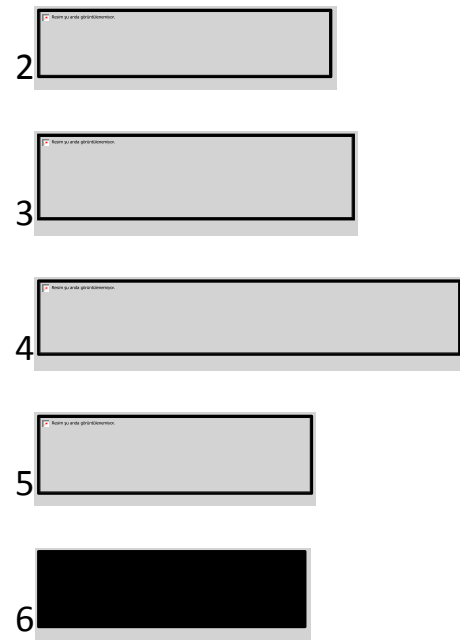

$7 E=-\sum_{i=1}^{N} s_{1} \log _{2} s_{i}$ 
yakın değerler yüksek yoğunlaşma olarak yorumlanmaktadır. Hakimiyet endeksi piyasadaki firmanın ya da firmalar grubunun büyüklüğünü ve sektördeki hakimiyet durumlarını ölçmektedir8. Bu endeks, bir piyasayı kontrol eden; tekel bir firma mı, oligopol firmalar mı yoksa oligopolistik bir firma grubu mu sorusunun cevabını aramak için kullanılmaktadır. Piyasadaki oligopol grubu belirlemek için hâkimiyet endeksi $k=1, \ldots . . . n$ 'e kadar hesaplanmaktadır9. Burada k* değeri oligopol grubu ile takip eden bankaları birbirinden ayıran değeri verirken, hâkimiyet endeksinin değeri ise söz konusu k'’a karşılık gelen değerdir (Yayla, 2007). Bankaların birlikte hareket etme eğilimini yansıtan Hause Endeksi10 0 ile 1 arasında değerler almaktadır. Sektörde tekel firma olması durumunda endeks değeri 1 olurken, birbirine yakın büyüklükte firma sayısının artması durumunda ise endeks değeri 0'a yaklaşmaktadır.

Çalışmada aktif büyüklüğü, kredi büyüklüğü ve mevduat büyüklüğü değişkenleri için üç ayrı Herfindahl- Hirschman Endeksi kullanılarak bankacılık sektörünün yoğunlaşma oranları tespit edilerek piyasa yapısı analiz edilmeye çalışılacaktır.

\section{AMPIRIK BULGULAR}

Türk bankacılık sektöründeki yoğunlaşma düzeyi hakkında ön bilgi edinebilmek için CR4 endeksinden faydalanılmıştır. CR4 endeksi piyasada faaliyet gösteren ilk 4 firmanın piyasanın ne kadarlık kısmına hakim olduğunu göstermektedir. CR4 endeksine göre sektördeki yoğunlaşma miktarını belirleyebilmek amacı ile 2004-2014 dönemine ait Türk mevduat bankalarının aktif büyüklükleri Tablo-1'de verilmiştir.
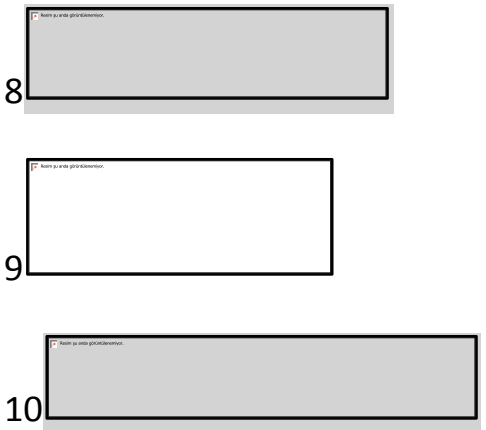
Tablo 1: Aktif Büyüklüklerine Göre Yoğunlaşma (2004-2014 Yılı, Milyon TL

\begin{tabular}{|c|c|c|c|c|c|c|c|c|c|c|c|c|c|c|c|c|c|c|c|c|c|c|}
\hline \multirow[b]{2}{*}{$\begin{array}{l}\text { MEVDUAT } \\
\text { BANKALARI }\end{array}$} & \multicolumn{2}{|c|}{2004} & \multicolumn{2}{|c|}{2005} & \multicolumn{2}{|c|}{2006} & \multicolumn{2}{|c|}{2007} & \multicolumn{2}{|c|}{2008} & \multicolumn{2}{|c|}{2009} & \multicolumn{2}{|c|}{2010} & \multicolumn{2}{|c|}{2011} & \multicolumn{2}{|c|}{2012} & \multicolumn{2}{|c|}{2013} & \multicolumn{2}{|c|}{2014} \\
\hline & $\begin{array}{l}\text { Aktif } \\
\text { Büyüklüğü }\end{array}$ & $\begin{array}{l}\text { Sektör } \\
\text { Payı } \\
\text { (\%) }\end{array}$ & $\begin{array}{l}\text { Aktif } \\
\text { Büyüklü̆ğü }\end{array}$ & \begin{tabular}{|l} 
Sektör \\
Payı \\
(\%)
\end{tabular} & $\begin{array}{c}\text { Aktif } \\
\text { Büyüklǚ̆ü }\end{array}$ & $\begin{array}{l}\text { Sektör } \\
\text { Payı } \\
\text { (\%) }\end{array}$ & \begin{tabular}{|l} 
Aktif \\
Büyüklüğü
\end{tabular} & $\begin{array}{l}\text { Sektör } \\
\text { Payı } \\
\text { (\%) }\end{array}$ & \begin{tabular}{|l} 
Aktif \\
Büyüklǚgü
\end{tabular} & $\begin{array}{l}\text { Sektör } \\
\text { Payı } \\
\text { (\%) }\end{array}$ & \begin{tabular}{|l} 
Aktif \\
Büyüklǚgü
\end{tabular} & $\begin{array}{l}\text { Sektör } \\
\text { Payı } \\
\text { (\%) }\end{array}$ & $\begin{array}{l}\text { Aktif } \\
\text { Büyüklü̆ğü }\end{array}$ & $\begin{array}{l}\text { Sektör } \\
\text { Payı } \\
\text { (\%) }\end{array}$ & $\begin{array}{c}\text { Aktif } \\
\text { Büyüklü̆ğü }\end{array}$ & $\begin{array}{l}\text { Sektör } \\
\text { Payı } \\
\text { (\%) }\end{array}$ & \begin{tabular}{|l} 
Aktif \\
Büyüklü̆ğü
\end{tabular} & $\begin{array}{l}\text { Sektör } \\
\text { Payı } \\
\text { (\%) }\end{array}$ & $\begin{array}{l}\text { Aktif } \\
\text { Büyüklü̆ğü }\end{array}$ & \begin{tabular}{|c|} 
Sektör \\
Payı \\
(\%)
\end{tabular} & $\begin{array}{l}\text { Aktif } \\
\text { Büyüklü̆ğü }\end{array}$ & \begin{tabular}{|c} 
Sektör \\
Payı \\
$(\%)$
\end{tabular} \\
\hline $\begin{array}{l}\text { Türkiye Cumhuriyeti } \\
\text { Ziraat Bankası A.Ş. }\end{array}$ & 56,994 & 20.86 & 65,050 & 18.19 & 71,904 & 15.79 & 80,942 & 9.16 & 104,412 & 15.71 & 124,529 & 16.57 & 151,160 & 16.63 & 161,669 & 14.59 & 162,868 & 13.26 & 207,530 & 13.59 & 247,600 & 14.18 \\
\hline $\begin{array}{l}\text { Türkiye Halk Bankası } \\
\text { A.Ş. }\end{array}$ & 25,709 & 9.41 & 27,053 & 7.57 & 34,425 & 7.56 & 40,234 & 4.55 & 51,096 & 7.69 & 60,650 & 8.07 & 72,942 & 8.02 & 91,124 & 8.23 & 108,282 & 8.82 & 139,944 & 9.16 & 155,423 & 8.90 \\
\hline $\begin{array}{l}\text { Türkiye Vakıflar } \\
\text { Bankası T.A.O. }\end{array}$ & 24,199 & 8.86 & 32,383 & 9.06 & 37,034 & 8.13 & 42,408 & 4.80 & 52,193 & 7.85 & 64,798 & 8.62 & 73,962 & 8.14 & 89,184 & 8.05 & 104,580 & 8.51 & 135,496 & 8.87 & 158,218 & 9.06 \\
\hline Akbank T.A.Ş. & 34,913 & 12.78 & 52,385 & 14.65 & 57,273 & 12.58 & 68,205 & 7.72 & 85,655 & 12.89 & 95,309 & 12.68 & 113,183 & 12.45 & 133,552 & 12.06 & 155,854 & 12.69 & 183,737 & 12.03 & 205,451 & 11.77 \\
\hline Anadolubank A.Ș. & 1,944 & 0.71 & 2,067 & 0.58 & 2,766 & 0.61 & 3,030 & 0.34 & 3,384 & 0.51 & 3,829 & 0.51 & 4,489 & 0.49 & 5,781 & 0.52 & 6,291 & 0.51 & 7,483 & 0.49 & 9,477 & 0.54 \\
\hline Şekerbank T.A.Ş. & 3,114 & 1.14 & 3,138 & 0.88 & 4,006 & 0.88 & 6,088 & 0.69 & 8,041 & 1.21 & 8,955 & 1.19 & 11,369 & 1.25 & 14,399 & 1.30 & 14,518 & 1.18 & 18,725 & 1.23 & 21,187 & 1.21 \\
\hline Tekstil Bankası A.Ş. & 1,362 & 0.50 & 1,959 & 0.55 & 2,785 & 0.61 & 2,902 & 0.33 & 2,953 & 0.44 & 2,133 & 0.28 & 2,573 & 0.28 & 3,489 & 0.31 & 3,677 & 0.30 & 3,849 & 0.25 & 3,656 & 0.21 \\
\hline Turkish Bank A.Ş. & 419 & 0.15 & 469 & 0.13 & 649 & 0.14 & 2,902 & 0.33 & 2,953 & 0.44 & 1,026 & 0.14 & 1,030 & 0.11 & 896 & 0.08 & 956 & 0.08 & 1,125 & 0.07 & 1,400 & 0.08 \\
\hline $\begin{array}{l}\text { Türk Ekonomi Bankası } \\
\text { A.Ş. }\end{array}$ & 3,566 & 1.31 & 5,422 & 1.52 & 8,282 & 1.82 & 11,801 & 1.34 & 14,736 & 2.22 & 15,064 & 2.00 & 19,031 & 2.09 & 38,092 & 3.44 & 43,532 & 3.54 & 53,409 & 3.50 & 62,992 & 3.61 \\
\hline $\begin{array}{l}\text { Türkiye Garanti } \\
\text { Bankası A.ş. }\end{array}$ & 26,268 & 9.61 & 36,468 & 10.20 & 50,287 & 11.05 & 67,578 & 7.65 & 88,941 & 13.38 & 105,462 & 14.03 & 123,963 & 13.64 & 146,642 & 13.24 & 160,192 & 13.04 & 196,896 & 12.89 & 218,919 & 12.54 \\
\hline Türkiye iş Bankası A.Ş. & 38,514 & 14.10 & 63,712 & 17.82 & 75,205 & 16.52 & 80,181 & 9.07 & 97,552 & 14.68 & 113,223 & 15.07 & 131,796 & 14.50 & 161,669 & 14.59 & 175,444 & 14.28 & 210,500 & 13.78 & 237,772 & 13.62 \\
\hline $\begin{array}{l}\text { Yapı ve Kredi Bankası } \\
\text { A.Ș. }\end{array}$ & 24,624 & 9.01 & 23,866 & 6.67 & 48,887 & 10.74 & 50,353 & 5.70 & 63,723 & 9.59 & 64,560 & 8.59 & 84,776 & 9.33 & 108,103 & 9.76 & 122,180 & 9.95 & 148,881 & 9.75 & 181,201 & 10.38 \\
\hline Alternatifbank A.Ş. & 1,174 & 0.43 & 1,470 & 0.41 & 1,972 & 0.43 & 2,597 & 0.29 & 3,745 & 0.56 & 3,629 & 0.48 & 4,259 & 0.47 & 6,445 & 0.58 & 7,969 & 0.65 & 10,380 & 0.68 & 10,659 & 0.61 \\
\hline $\begin{array}{l}\text { Arap Türk Bankası } \\
\text { A.S. }\end{array}$ & 331 & 0.12 & 361 & 0.10 & 373 & 0.08 & 356,689 & 40.37 & 799 & 0.12 & 966 & 0.13 & 1,141 & 0.13 & 3,013 & 0.27 & 2,748 & 0.22 & 3,352 & 0.22 & 3,717 & 0.21 \\
\hline Citibank A.Ş. & 1,922 & 0.70 & 2,531 & 0.71 & 6,105 & 1.34 & 4,194 & 0.47 & 5,451 & 0.82 & 4,878 & 0.65 & 6,284 & 0.69 & 7,227 & 0.65 & 7,420 & 0.60 & 6,469 & 0.42 & 7,325 & 0.42 \\
\hline Denizbank A.Ş. & 6,705 & 2.45 & 9,358 & 2.62 & 11,493 & 2.52 & 14,912 & 1.69 & 19,225 & 2.89 & 21,205 & 2.82 & 27,660 & 3.04 & 35,983 & 3.25 & 44,198 & 3.60 & 59,427 & 3.89 & 69,474 & 3.98 \\
\hline Deutsche Bank A.Ş. & 365 & 0.13 & 301 & 0.08 & 882 & 0.19 & 744 & 0.08 & 684 & 0.10 & 1,910 & 0.25 & 3,051 & 0.34 & 2,242 & 0.20 & 1,297 & 0.11 & 2,360 & 0.15 & 2,922 & 0.17 \\
\hline Finans Bank A.ş. & 8,630 & 3.16 & 12,314 & 3.44 & 17,895 & 3.93 & 20,882 & 2.36 & 26,573 & 4.00 & 29,318 & 3.90 & 38,087 & 4.19 & 46,199 & 4.17 & 54,402 & 4.43 & 66,010 & 4.32 & 75,206 & 4.31 \\
\hline HSBC Bank A.Ş. & 5,283 & 1.93 & 7,856 & 2.20 & 10,272 & 2.26 & 13,432 & 1.52 & 14,696 & 2.21 & 13,850 & 1.84 & 17,737 & 1.95 & 24,132 & 2.18 & 25,299 & 2.06 & 36,229 & 2.37 & 33,821 & 1.94 \\
\hline ING Bank A.Ş. & 6,154 & 2.25 & 8,377 & 2.34 & 11,815 & 2.60 & 12,541 & 1.42 & 16,503 & 2.48 & 15,233 & 2.03 & 17,299 & 1.90 & 21,066 & 1.90 & 25,115 & 2.04 & 33,395 & 2.19 & 38,014 & 2.18 \\
\hline Bank Mellat & 179 & 0.07 & 194 & 0.05 & 225 & 0.05 & 218 & 0.02 & 328 & 0.05 & 395 & 0.05 & 1,835 & 0.20 & 3,540 & 0.32 & 408 & 0.03 & 335 & 0.02 & 326 & 0.02 \\
\hline Habib Bank Limited & 27 & 0.01 & 26 & 0.01 & 43 & 0.01 & 48 & 0.01 & 328 & 0.05 & 73 & 0.01 & 75 & 0.01 & 79 & 0.01 & 74 & 0.01 & 93 & 0.01 & 78 & 0.00 \\
\hline $\begin{array}{l}\text { JPMorgan Chase Bank } \\
\text { N.A. }\end{array}$ & 430 & 0.16 & 353 & 0.10 & 221 & 0.05 & 175 & 0.02 & 243 & 0.04 & 199 & 0.03 & 702 & 0.08 & 2,224 & 0.20 & 429 & 0.03 & 330 & 0.02 & 384 & 0.02 \\
\hline SociétéGénérale (SA) & 387 & 0.14 & 445 & 0.12 & 445 & 0.10 & 576 & 0.07 & 476 & 0.07 & 360 & 0.05 & 674 & 0.07 & 992 & 0.09 & 594 & 0.05 & 1,258 & 0.08 & 831 & 0.05 \\
\hline SEKTÖR TOPLAMI & 273,214 & 100.00 & 357,558 & 100.00 & 455,244 & 100.00 & 883,636 & 100.00 & 664,690 & 100.00 & 751,554 & 100.00 & 909,078 & 100.00 & $1,107,740$ & 100.00 & $1,228,327$ & 100.00 & $1,527,214$ & \begin{tabular}{|l|l|}
100.00 \\
\end{tabular} & $1,746,053$ & 100.00 \\
\hline
\end{tabular}


Yoğunlaşma oranlarının değerlendirilmesinde genel itibariyle CR4 endeksi dikkate alınmaktadır. CR4 endeksine göre, bir piyasadaki ilk dört firmanın sektörden aldığı pay\%30'un üzerinde ise o sektörde yoğunlaşma oranı yüksek yüzeyde demektir.

\begin{tabular}{|l|l|l|l|l|l|l|l|l|l|l|l|}
\hline \multicolumn{10}{|c|}{ Tablo 2: CR4 Endeksine Göre Yoğunlaşma Oranları } \\
\hline & $\mathbf{2 0 0 4}$ & $\mathbf{2 0 0 5}$ & $\mathbf{2 0 0 6}$ & $\mathbf{2 0 0 7}$ & $\mathbf{2 0 0 8}$ & $\mathbf{2 0 0 9}$ & $\mathbf{2 0 1 0}$ & $\mathbf{2 0 1 1}$ & $\mathbf{2 0 1 2}$ & $\mathbf{2 0 1 3}$ & $\mathbf{2 0 1 4}$ \\
\hline CR2 & 34.96 & 36.01 & 32.31 & 18.23 & 30.38 & 31.63 & 31.13 & 29.19 & 27.54 & 27.37 & 27.8 \\
\hline CR3 & 47.74 & 50.66 & 44.89 & 25.95 & 43.77 & 45.67 & 44.76 & 42.43 & 40.58 & 40.26 & 40.34 \\
\hline CR4 & 57.35 & 60.86 & 55.94 & 33.6 & 56.65 & 58.35 & 57.21 & 54.48 & 53.27 & 52.3 & 52.1 \\
\hline CR10 & 92.5 & 92.56 & 91.43 & 54.12 & 91.15 & 92.38 & 92.02 & 91.38 & 92.12 & 91.79 & 92.34 \\
\hline
\end{tabular}

Bu doğrultuda Tablo-2'de 2004-2014 dönemine ait CR4 değerleri incelendiğinde Türk bankacilık sektöründe yoğunlaşma

oranının oldukça yüksek olduğunu söyleyebiliriz. 24 mevduat bankası içerisinde, ilk 4 bankanın 2007 yılı haricinde, sektörün \%50'sinden fazla paya sahip olması Türk bankacılık piyasasının oligopolistik bir yapıda olduğu izlenimini vermektedir. Ayrıca Tablo-2'deki verilere göre, sektörde ilk iki bankanın \%30, ilk üç bankanın \%40 ve ilk 10 bankanın \%92 civarında paya sahip olması Türk bankacılık sektörünün oligopol yapıya sahip olduğu görüşünü desteklemektedir.

CR4 endeks değerlerinden elde edilen sonuçların test edilerek net sonuca ulaşılması amacı ile HHE endeks değerleri hesaplanmıştır. Sektöre ait mevduat bankalarının piyasa paylarının karesi alınıp, elde edilen değerlerin toplanması ile bulunan HHE yoğunlaşmanın ölçülmesinde en çok tercih edilen hesaplamalardan biridir. Bir sektörde HHE endeks değerinin 1800'ü aşması yoğunlaşmanın başladığını göstermektedir. Türk bankacılık sektörünün Aktif büyüklüğü açısından 2004-2014 dönemine ait HHE endeks değerlerinin yer aldığı Tablo-3'te HHE değerlerinin 1800'ün altında seyretmesi Türk mevduat bankalarında yoğunlaşmanın olmadığını göstermektedir. CR4 endeksinde Türk mevduat bankalarının yoğunlaşma oranının yüksek olduğu sonucuna ulaşılırken, HHE endeksine göre Türk mevduat bankalarında yoğunlaşmanın olmadığı tespit edilmiştir. 
Tablo 3: Herfindahl-Hirschman Endeksi Açısından Türk Bankacılık Sektörünün Aktif Büyüklüğüne Göre Yoğunlaşma

\begin{tabular}{|c|c|c|c|c|c|c|c|c|c|c|c|c|}
\hline $\begin{array}{l}\text { Sira } \\
\text { No }\end{array}$ & MEVDUAT BANKALARI & 2004 & 2005 & 2006 & 2007 & 2008 & 2009 & 2010 & 2011 & 2012 & 2013 & 2014 \\
\hline 1 & $\begin{array}{l}\text { Türkiye Cumhuriyeti Ziraat } \\
\text { Bankası A.Ş. }\end{array}$ & 435.17 & 330.98 & 249.47 & 235.63 & 246.76 & 274.55 & 276.48 & 213 & 175.81 & 184.66 & 201.09 \\
\hline 2 & Türkiye İş Bankası A.Ş. & 198.71 & 317.51 & 272.9 & 231.22 & 215.39 & 226.96 & 210.19 & 213 & 204.01 & 189.98 & 185.44 \\
\hline 3 & Akbank T.A.Ş. & 163.3 & 214.64 & 158.27 & 167.3 & 166.06 & 160.82 & 155.01 & 145.35 & 160.99 & 144.74 & 138.45 \\
\hline 4 & Türkiye Garanti Bankası A.Ş. & 92.44 & 104.02 & 122.02 & 164.25 & 179.05 & 196.91 & 185.95 & 175.24 & 170.08 & 166.22 & 157.2 \\
\hline 5 & Türkiye Halk Bankası A.Ş. & 88.55 & 57.24 & 57.18 & 58.22 & 59.09 & 65.12 & 64.38 & 67.67 & 77.71 & 83.97 & 79.23 \\
\hline 6 & Yapı ve Kredi Bankası A.Ş. & 81.23 & 44.55 & 115.32 & 91.19 & 91.91 & 73.79 & 86.97 & 95.24 & 98.94 & 95.03 & 107.7 \\
\hline 7 & Türkiye Vakıflar Bankası T.A.O. & 78.45 & 82.02 & 66.18 & 64.68 & 61.66 & 74.34 & 66.19 & 64.82 & 72.49 & 78.71 & 82.11 \\
\hline 8 & Finans Bank A.Ş. & 9.98 & 11.86 & 15.45 & 15.68 & 15.98 & 15.22 & 17.55 & 17.39 & 19.62 & 18.68 & 18.55 \\
\hline 9 & Denizbank A.Ş. & 6.02 & 6.85 & 6.37 & 8 & 8.37 & 7.96 & 9.26 & 10.55 & 12.95 & 15.14 & 15.83 \\
\hline 10 & ING Bank A.Ş. & 5.07 & 5.49 & 6.74 & 5.66 & 6.16 & 4.11 & 3.62 & 3.62 & 4.18 & 4.78 & 4.74 \\
\hline 11 & HSBC Bank A.Ş. & 3.74 & 4.83 & 5.09 & 6.49 & 4.89 & 3.4 & 3.81 & 4.75 & 4.24 & 5.63 & 3.75 \\
\hline 12 & Türk Ekonomi Bankası A.Ş. & 1.7 & 2.3 & 3.31 & 5.01 & 4.92 & 4.02 & 4.38 & 11.82 & 12.56 & 12.23 & 13.02 \\
\hline 13 & Şekerbank T.A.Ş. & 1.3 & 0.77 & 0.77 & 1.33 & 1.46 & 1.42 & 1.56 & 1.69 & 1.4 & 1.5 & 1.47 \\
\hline 14 & Anadolubank A.Ş. & 0.51 & 0.33 & 0.37 & 0.33 & 0.26 & 0.26 & 0.24 & 0.27 & 0.26 & 0.24 & 0.29 \\
\hline 15 & Citibank A.Ş. & 0.49 & 0.5 & 1.8 & 0.63 & 0.67 & 0.42 & 0.48 & 0.43 & 0.36 & 0.18 & 0.18 \\
\hline 16 & Tekstil Bankası A.Ş. & 0.25 & 0.3 & 0.37 & 0.3 & 0.2 & 0.08 & 0.08 & 0.1 & 0.09 & 0.06 & 0.04 \\
\hline 17 & Alternatifbank A.ş. & 0.18 & 0.17 & 0.19 & 0.24 & 0.32 & 0.23 & 0.22 & 0.34 & 0.42 & 0.46 & 0.37 \\
\hline 18 & Turkish Bank A.Ş. & 0.02 & 0.02 & 0.02 & 0.3 & 0.2 & 0.02 & 0.01 & 0.01 & 0.01 & 0.01 & 0.01 \\
\hline 19 & Deutsche Bank A.Ş. & 0.02 & 0.01 & 0.04 & 0.02 & 0.01 & 0.06 & 0.11 & 0.04 & 0.01 & 0.02 & 0.03 \\
\hline 20 & JPMorgan Chase Bank N.A. & 0.02 & 0.01 & 0 & 0 & 0 & 0 & 0.01 & 0.04 & 0 & 0 & 0 \\
\hline 21 & SociétéGénérale (SA) & 0.02 & 0.02 & 0.01 & 0.01 & 0.01 & 0 & 0.01 & 0.01 & 0 & 0.01 & 0 \\
\hline 22 & Arap Türk Bankası A.Ş. & 0.01 & 0.01 & 0.01 & 0 & 0.01 & 0.02 & 0.02 & 0.07 & 0.05 & 0.05 & 0.05 \\
\hline 23 & Bank Mellat & 0 & 0 & 0 & 0 & 0 & 0 & 0.04 & 0.1 & 0 & 0 & 0 \\
\hline 24 & Habib Bank Limited & 0 & 0 & 0 & 0 & 0 & 0 & 0 & 0 & 0 & 0 & 0 \\
\hline \multicolumn{2}{|r|}{ SEKTÖR TOPLAMI } & 1167.2 & 1184.44 & 1081.88 & 1056.51 & 1063.38 & 1109.72 & 1086.56 & 1025.54 & 1016.18 & 1002.3 & 1009.6 \\
\hline
\end{tabular}

HHE analizi sonucunda Türk mevduat bankalarının aktif büyüklüğü açısından yoğunlaşmanın olmadığı bulgusu beklentilerin dışında gerçekleşen bir sonuçtur. Bu sonucun daha iyi anlaşılabilmesi için Türk bankacılık sektöründe faaliyet gösteren mevduat bankalarının kredi ve mevduat büyüklükleri HHE endeksi ile incelenmiştir. Tablo-4'te yıllar itibariyle sektör toplamına baktığımızda toplanan mevduat miktarı açısından da HHE endeksine göre Türk bankacılık sektöründe yoğunlaşma olmadığı görülmektedir.

\begin{tabular}{|c|c|c|c|c|c|c|c|c|c|c|c|c|}
\hline $\begin{array}{l}\text { Sira } \\
\text { No }\end{array}$ & MEVDUAT & 2004 & 2005 & 2006 & 2007 & 2008 & 2009 & 2010 & 2011 & 2012 & 2013 & 2014 \\
\hline 1 & $\begin{array}{l}\text { Türkiye Cumhuriyeti Ziraat } \\
\text { Bankası A.Ş. }\end{array}$ & 345.9 & 268.5 & 219.9 & 208.0 & 218.8 & 243.2 & 247.0 & 191.6 & 157.4 & 161.0 & 171.9 \\
\hline 2 & Türkiye İş Bankası A.ş. & 157.9 & 257.6 & 240.6 & 204.2 & 191.0 & 201.0 & 187.7 & 194.0 & 182.7 & 165.7 & 158.6 \\
\hline 3 & Akbank T.A.Ş. & 129.8 & 174.1 & 139.5 & 147.7 & 147.2 & 142.5 & 138.5 & 132.4 & 144.1 & 126.2 & 118.4 \\
\hline 4 & Türkiye Garanti Bankası A.Ş. & 73.5 & 84.4 & 107.6 & 145.0 & 158.8 & 174.4 & 166.1 & 159.6 & 152.3 & 145.0 & 134.4 \\
\hline 5 & Türkiye Halk Bankası A.ş. & 70.4 & 46.4 & 50.4 & 51.4 & 52.4 & 57.7 & 57.5 & 61.6 & 69.6 & 73.2 & 67.7 \\
\hline 6 & Yapı ve Kredi Bankası A.Ş. & 64.6 & 36.1 & 101.7 & 80.5 & 81.5 & 65.4 & 77.7 & 86.7 & 88.6 & 82.9 & 92.1 \\
\hline 7 & $\begin{array}{l}\text { Türkiye Vakıflar Bankası } \\
\text { T.A.O. }\end{array}$ & 62.4 & 66.5 & 58.3 & 57.1 & 54.7 & 65.8 & 59.1 & 59.0 & 64.9 & 68.6 & 70.2 \\
\hline 8 & Finans Bank A.Ş. & 7.9 & 9.6 & 13.6 & 13.8 & 14.2 & 13.5 & 15.7 & 15.8 & 17.6 & 16.3 & 15.9 \\
\hline 9 & Denizbank A.Ş. & 4.8 & 5.6 & 5.6 & 7.1 & 7.4 & 7.1 & 8.3 & 9.6 & 11.6 & 13.2 & 13.5 \\
\hline
\end{tabular}




\begin{tabular}{|c|c|c|c|c|c|c|c|c|c|c|c|c|}
\hline 10 & ING Bank A.Ş. & 4.0 & 4.5 & 5.9 & 5.0 & 5.5 & 3.6 & 3.2 & 3.3 & 3.7 & 4.2 & 4.1 \\
\hline 11 & HSBC Bank A.Ş. & 3.0 & 3.9 & 4.5 & 5.7 & 4.3 & 3.0 & 3.4 & 4.3 & 3.8 & 4.9 & 3.2 \\
\hline 12 & Türk Ekonomi Bankası A.Ş. & 1.4 & 1.9 & 2.9 & 4.4 & 4.4 & 3.6 & 3.9 & 10.8 & 11.2 & 10.7 & 11.1 \\
\hline 13 & Şekerbank T.A.Ş. & 1.0 & 0.6 & 0.7 & 1.2 & 1.3 & 1.3 & 1.4 & 1.5 & 1.3 & 1.3 & 1.3 \\
\hline 14 & Anadolubank A.Ş. & 0.4 & 0.3 & 0.3 & 0.3 & 0.2 & 0.2 & 0.2 & 0.2 & 0.2 & 0.2 & 0.3 \\
\hline 15 & Citibank A.ş. & 0.4 & 0.4 & 1.6 & 0.6 & 0.6 & 0.4 & 0.4 & 0.4 & 0.3 & 0.2 & 0.2 \\
\hline 16 & Tekstil Bankası A.Ş. & 0.2 & 0.2 & 0.3 & 0.3 & 0.2 & 0.1 & 0.1 & 0.1 & 0.1 & 0.1 & 0.0 \\
\hline 17 & Alternatifbank A.ş. & 0.1 & 0.1 & 0.2 & 0.2 & 0.3 & 0.2 & 0.2 & 0.3 & 0.4 & 0.4 & 0.3 \\
\hline 18 & JPMorgan Chase Bank N.A. & 0.0 & 0.0 & 0.0 & 0.0 & 0.0 & 0.0 & 0.0 & 0.0 & 0.0 & 0.0 & 0.0 \\
\hline 19 & Turkish Bank A.ş. & 0.0 & 0.0 & 0.0 & 0.0 & 0.0 & 0.0 & 0.0 & 0.0 & 0.0 & 0.0 & 0.0 \\
\hline 20 & SociétéGénérale (SA) & 0.0 & 0.0 & 0.0 & 0.0 & 0.0 & 0.0 & 0.0 & 0.0 & 0.0 & 0.0 & 0.0 \\
\hline 21 & Deutsche Bank A.Ş. & 0.0 & 0.0 & 0.0 & 0.0 & 0.0 & 0.1 & 0.1 & 0.0 & 0.0 & 0.0 & 0.0 \\
\hline 22 & Arap Türk Bankası A.Ş. & 0.0 & 0.0 & 0.0 & 0.0 & 0.0 & 0.0 & 0.0 & 0.1 & 0.0 & 0.0 & 0.0 \\
\hline 23 & Bank Mellat & 0.0 & 0.0 & 0.0 & 0.0 & 0.0 & 0.0 & 0.0 & 0.1 & 0.0 & 0.0 & 0.0 \\
\hline 24 & Habib Bank Limited & 0.0 & 0.0 & 0.0 & 0.0 & 0.0 & 0.0 & 0.0 & 0.0 & 0.0 & 0.0 & 0.0 \\
\hline & SEKTÖR TOPLAMI & 927.741 & 960.928 & 953.772 & 932.577 & 942.756 & 982.985 & 970.554 & 931.713 & 909.821 & 874.111 & 863.192 \\
\hline
\end{tabular}

Türk bankacılık sektöründe bankaların kullandırmış olduğu kredi miktarının gösterildiği Tablo-5'e baktığımızda, yine HHE endeksine Türk bankacılık sektöründe yoğunlaşmanın olmadığı görülmektedir.

Tablo 5: Herfindahl-Hirschman Endeksi Açısından Türk Bankacılık Sektörünün Kredi Büyüklüğüne Göre Yoğunlaşma

\begin{tabular}{|c|c|c|c|c|c|c|c|c|c|c|c|c|}
\hline $\begin{array}{l}\text { Sira } \\
\text { No }\end{array}$ & KREDi & 2004 & 2005 & 2006 & 2007 & 2008 & 2009 & 2010 & 2011 & 2012 & 2013 & 2014 \\
\hline 1 & Akbank T.A.Ş. & 157.076 & 208.597 & 168.864 & 174.202 & 146.272 & 108.668 & 108.053 & 112.014 & 129.952 & 118.775 & 108.454 \\
\hline 2 & Türkiye İş Bankası A.Ş. & 145.466 & 183.786 & 186.981 & 146.799 & 168.386 & 160.931 & 159.330 & 190.227 & 194.150 & 177.457 & 166.037 \\
\hline 3 & Türkiye Garanti Bankası A.Ş. & 103.463 & 122.452 & 157.312 & 176.110 & 185.026 & 170.375 & 162.299 & 159.188 & 142.604 & 136.556 & 122.811 \\
\hline 4 & Yapı ve Kredi Bankası A.Ş. & 94.873 & 54.566 & 106.502 & 103.333 & 111.101 & 98.726 & 106.911 & 104.108 & 97.096 & 89.436 & 101.702 \\
\hline 5 & $\begin{array}{l}\text { Türkiye Cumhuriyeti Ziraat } \\
\text { Bankası A.Ş. }\end{array}$ & 78.293 & 76.935 & 63.460 & 59.341 & 70.636 & 92.904 & 127.433 & 115.624 & 86.285 & 119.575 & 137.629 \\
\hline 6 & $\begin{array}{l}\text { Türkiye Vakıflar Bankası } \\
\text { T.A.O. }\end{array}$ & 60.980 & 60.499 & 68.464 & 70.033 & 69.114 & 82.335 & 77.721 & 74.428 & 78.511 & 72.976 & 74.745 \\
\hline 7 & Finans Bank A.Ş. & 25.278 & 24.758 & 26.261 & 25.544 & 23.743 & 21.208 & 23.866 & 20.765 & 22.458 & 17.700 & 17.253 \\
\hline 8 & Türkiye Halk Bankası A.Ş. & 17.674 & 16.507 & 28.521 & 41.749 & 49.586 & 72.572 & 75.777 & 71.616 & 73.435 & 69.808 & 70.773 \\
\hline 9 & HSBC Bank A.Ş. & 11.635 & 11.189 & 11.906 & 11.104 & 7.024 & 5.276 & 3.612 & 4.336 & 4.022 & 3.536 & 2.554 \\
\hline 10 & ING Bank A.Ş. & 11.387 & 11.072 & 11.264 & 9.209 & 9.061 & 8.342 & 5.733 & 5.359 & 6.005 & 5.811 & 5.375 \\
\hline 11 & Denizbank A.Ş. & 6.483 & 8.872 & 9.796 & 13.765 & 12.093 & 13.833 & 13.158 & 11.393 & 13.441 & 14.476 & 12.692 \\
\hline 12 & Türk Ekonomi Bankası A.Ş. & 2.356 & 3.686 & 5.156 & 5.991 & 5.373 & 5.568 & 5.335 & 14.912 & 14.904 & 14.102 & 14.080 \\
\hline 13 & Tekstil Bankası A.Ş. & 1.588 & 0.549 & 0.837 & 1.661 & 1.711 & 1.658 & 1.896 & 1.641 & 1.682 & 1.768 & 1.463 \\
\hline 14 & Citibank A.ş. & 0.618 & 0.544 & 0.657 & 0.485 & 0.469 & 0.300 & 0.205 & 0.163 & 0.151 & 0.036 & 0.040 \\
\hline 15 & Anadolubank A.Ş. & 0.491 & 0.382 & 0.399 & 0.396 & 0.285 & 0.407 & 0.354 & 0.316 & 0.295 & 0.246 & 0.267 \\
\hline 16 & Alternatifbank A.Ş. & 0.320 & 0.329 & 0.380 & 0.442 & 0.417 & 0.512 & 0.407 & 0.426 & 0.457 & 0.399 & 0.425 \\
\hline 17 & Bank Mellat & 0.010 & 0.005 & 0.003 & 0.001 & 0.002 & 0.004 & 0.048 & 0.008 & 0.000 & 0.000 & 0.000 \\
\hline 18 & Şekerbank T.A.Ş. & 0.008 & 0.047 & 0.085 & 0.069 & 0.058 & 0.036 & 0.016 & 0.101 & 0.175 & 0.260 & 0.262 \\
\hline 19 & Arap Türk Bankası A.Ş. & 0.005 & 0.003 & 0.002 & 0.002 & 0.008 & 0.008 & 0.009 & 0.017 & 0.009 & 0.020 & 0.013 \\
\hline 20 & Turkish Bank A.Ş. & 0.002 & 0.003 & 0.003 & 0.002 & 0.003 & 0.004 & 0.007 & 0.002 & 0.003 & 0.003 & 0.005 \\
\hline
\end{tabular}




\begin{tabular}{|c|c|c|c|c|c|c|c|c|c|c|c|c|}
\hline 21 & SociétéGénérale (SA) & 0.001 & 0.001 & 0.002 & 0.001 & 0.001 & 0.002 & 0.005 & 0.004 & 0.003 & 0.000 & 0.000 \\
\hline 22 & Deutsche Bank A.Ş. & 0.000 & 0.002 & 0.001 & 0.004 & 0.001 & 0.000 & 0.001 & 0.006 & 0.002 & 0.008 & 0.008 \\
\hline 23 & Habib Bank Limited & 0.000 & 0.000 & 0.000 & 0.000 & 0.000 & 0.000 & 0.000 & 0.000 & 0.000 & 0.000 & 0.000 \\
\hline 24 & JPMorgan Chase Bank N.A. & 0.000 & 0.000 & 0.000 & 0.000 & 0.000 & 0.000 & 0.000 & 0.000 & 0.000 & 0.000 & 0.000 \\
\hline & SEKTÖR TOPLAMI & 718.006 & 784.784 & 846.857 & 840.241 & 860.371 & 843.669 & 872.175 & 886.653 & 865.642 & 842.948 & 836.588 \\
\hline
\end{tabular}

Elde edilen bulgular ışığında, Türk bankacılık sektörü piyasa yapısının Tam rekabet, oligopol ve monopol piyasa yapısı özelliklerini tam manasıyla barındırmadığı, dolayısı ile Türk bankacılık sektörünün monopolcü rekabet piyasa yapısı varsayımları ile daha uyumlu bir yapıda olduğu tespit edilmiştir.

\section{SONUÇ}

Bu çalışmada 2004-2014 yılları için Türk bankacılık sisteminin piyasa yapısı yoğunlaşma endeksleri kullanılarak test edilmiştir. 24 ticaret bankası için bankacılık sektörünün temel göstergeleri olan mevduat, kredi ve aktif büyüklükleri temel alınarak yoğunlaşma oranları hesaplanmıştır. Yoğunlaşma oranları bir piyasanın tam rekabet, oligopol, monopol ya da monopolcü rekabet ..gibi hangi piyasa yapısına uygun olduğunu gösteren önemli bir ölçüttür.

CR4 değerlerine göre Türk bankacılık sisteminin oligopolistik bir yapıda olduğu izlenimini vardır. Ancak HerfindahlHirschman Endeksi hesaplanarak daha gerçekçi sonuçlar elde edilmiştir. Aktif, kredi ve mevduat büyüklükleri için Herfindahl-Hirschman Endeksi sonuçlarına göre Türk Bankacılık sisteminin monopolcü rekabet piyasa yapısı varsayımları ile daha uyumlu bir yapıda olduğu tespit edilmiştir. Bu sonuç Claessens ve Laeven (2004), Abbasoğlu vd. (2007), Özcan (2012), Uzgören ve Tarhan (2012)'nin bulgularını desteklemektedir.

Piyasa yapısı açısından, tam rekabet piyasasından sonra kaynakların en etkin kullanıldığı piyasa yapısı monopolcü rekabet piyasa yapısıdır. Bu açıdan Türk bankacılık sisteminin bu piyasa yapısında olması kaynakların aktarma kanalları arasında tam aktarıldığı anlamına gelmektedir. Bu durumun bankacılık sektörünün verimliliğini olumlu etkileyeceğini söyleyebiliriz.. Ancak monopolcü rekabet piyasalarında yaşanan yoğun rekabet ve rekabetin yarattığı bankaların birleşme güdüsü bankaları daha fazla risk almak zorunda bırakabilir. Ayrıca çok sayıda satıcı $n$ sayıda alıcının yer aldığı monopolcü rekabet piyasa yapısına sahip olan Türk bankacılık sektöründe, küçük ölçekli çok sayıda bankanın yer alması denetimi zorlaştırmaktadır.

\section{KAYNAKLAR}

Abbasoğlu, Osman Furkan ve Diğerleri, (2007), Concentration, Competition, Efficiency and Profitability of the Turkish Banking Sector in the Post-Crises Period, Munich Personal RePEc Archive, No 5494.

Aydınlı, İ. (1996), Türk Bankacılık Sistemi Piyasa Yapısı, Sermaye Piyasası Kurulu Yayını, No: 40, Ankara.

Bikker, J. A. ve J. M., GROENEVELD (1998), Competition and Concentration in the EU Banking Industry, De Nederlandsche Bank, Research Series Supervision, no 8.

Bikker, J.A. (2003), Testing for Imperfect Competition on EU Deposit and Loan Marketswith Bresnehan's Market Power Model. De Nederlandsche Bank Research Series Supervision, No 52.

Bikker, J.A. ve K. HAAF (2000), Measures of Competition and Concentration in The Banking Industry: A Riview of The Literature. De Nederlandsche Bank Research Series Supervision, No: 27, September.

Bikker, J.A. ve K. HAAF (2002a), Competition, Concentration and Their Relationship: An Empirical Analysis of the Banking Industry. Journal of Banking and Finance, (26): 2191-2214.

Casu, B. ve C. GIRARDONE (2006), Bank Competition, Concentration and Efficiency in the Single European Market, The Manchester School, 74.4.

Claessens, S. ve L. LAEVEN (2004), What Drives Bank Competition? Some International Evidence, Journal of Money, Creditand Banking, Vol. 36, No. 3.

Coşkun, M.N. ve Diğ. (2012), Türkiye'de Bankacılık Sektörü Piyasa Yapısı, Firma Davranışları ve Rekabet Analizi, Türkiye Bankalar Birliği, Yayın No: 280, İstanbul.

Çelik, Tuncay ve KAPLAN, Muhittin (2010), Türk Bankacılık Sektöründe Etkinlik ve Rekabet: 2002-2007, Sosyo ekonomi, 2010-2.

Fiona, T. (2006), An Emprical Investigation of TheEffects of Concetration on Profitability Amaong US Banks, MPRA Paper, No:13731, pp.189.

Gelos, R. G. ve J. ROLDOS (2002), Consolidation and Market Structure in Emerging Markets Banking Systems, International Monetary Fund.

Güneş, M.; KÖSE, A. ve E. YELDAN (1997), Input-output tablosu tasnifine göre Türkiye imalat sanayinde yoğunlaşma eğilimleri 1985-1993. Ekonomik Yaklaşım, 8(26), 33-47.

Kasman, Adnan (2001), The Profit-Structure Relationship in the Turkish Banking Industry Using Direct Measures of Efficiency. Ege Akademik Bakıfl Dergisi, 1(1):141-164. 
Kostakoğlu, Fatih (2015), İnternet Servis Sağlayıııları Piyasasına Yönelik Yoğunlaşma Analizi, Uluslararası Yönetim İktisat ve Iş̧letme Dergisi, Cilt 11, Sayı 25.

Mirzaei, A., MOORE, T., ve G. LiU (2013), Does Market StructureMatter on Banks' Profitability and Stability? Emerging vs. Advanced Economies, Journal of Banking\& Finance, 37(8), 2920-2937.

Nathan, A.,and E.H. NEAVE (1989), 'Competition and Contestability in Canada's Financial System Empirical Results', Canadian Journal of Economics22, pp. 576-594.

Northcott, C.A. (2004), Competition in Banking: A Review of the Literature. Bank of Canada Working Paper, No: 2004-24.

Özcan, Abdulvahap (2012), Türkiye'de Ticari Bankacılık Sektöründe Rekabet Düzeyinin Belirlenmesi (2002-2009), C.Ü. İktisadi ve İdari Bilimler Dergisi, Cilt 13, Sayı 1.

Parkin, M. (2003), Economics (6. Edition), USA: Pearson Education.

Rhoades, S. (1993), The Herfindahl- Hirschman index, Federal Reserve Bulletin, 79 (March), 188-189.

Shaffer, S. (1982), Competition, Conduct and Demand Elasticity, EconomicLetters10, pp. 167-171.

Shy, O. (1995), Industrial Organization: Theory and Applications. New York: MIT Press.

Suominen, M. (1994), Measuring Competition in Banking: A Two-Product Model, Scandinavian Journal of Economics, 96 (1): $95-110$.

Uzgören, Ergin ve TARHAN, Ali (2012), Türkiye'de Bankacılık Piyasasında Yoğunlaşma-CR4 ve Herfindahl-Hirschman Endeksleri Analiz-, Akademik Bakış Dergisi, Sayı:28, ISSN:1694-528X

Weill, L. (2004), On the Relationship Between Competition and Efficiency in the EU Banking Sectors, Kreditund Kapital.

Yayla, Münür (2007), Türk Bankacılık Sektöründe Yoğunlaşma ve Rekabet BDDK Bankacılık ve Finansal Piyasalar Dergisi Sayı:1, Cilt: 1, ss.3559.

YILDIRIM, K.; EŞKINAT, R.; KABASAKAL, A. ve ERDOĞAN, M. (2012), Endüstriyel ekonomi, 5. Baskı, Ankara: Pelikan Yayıncılık.

https://www.tbb.org.tr/tr/bankacilik/banka-ve-sektor-bilgileri/istatistiki-raporlar/59 